\title{
The role of silicon-based nanofillers and polymer crystallization on the breakdown behaviors of polyethylene blend nanocomposites
}

Article

Accepted Version

Kamarudin, S. N., Lau, K. Y., Tan, C. W. and Ching, K. Y. (2020) The role of silicon-based nanofillers and polymer crystallization on the breakdown behaviors of polyethylene blend nanocomposites. NANO, 15 (8). 2050097. ISSN 17937094 doi: https://doi.org/10.1142/S1793292020500976 Available at https://centaur.reading.ac.uk/102026/

It is advisable to refer to the publisher's version if you intend to cite from the work. See Guidance on citing.

To link to this article DOI: http://dx.doi.org/10.1142/S1793292020500976

Publisher: World Scientific

All outputs in CentAUR are protected by Intellectual Property Rights law, including copyright law. Copyright and IPR is retained by the creators or other copyright holders. Terms and conditions for use of this material are defined in the End User Agreement. 


\section{CentAUR}

Central Archive at the University of Reading

Reading's research outputs online 


\title{
The Role of Silicon-Based Nanofillers and Polymer Crystallization on the Breakdown Behaviors of Polyethylene Blend Nanocomposites
}

\author{
Siti Noorhazirah Kamarudin ${ }^{\dagger}$, Kwan Yiew Lau ${ }^{\dagger, *}$, Chee Wei Tan ${ }^{\dagger}$, Kuan Yong Ching \\ ${ }^{\dagger}$ School of Electrical Engineering, Universiti Teknologi Malaysia \\ Johor Bahru, 81310, Malaysia \\ University of Reading Malaysia \\ Iskandar Puteri, 79200, Malaysia \\ *kwanyiew@utm.my \\ Received 10 March 2020 \\ Revised 10 May 2020
}

\begin{abstract}
Good breakdown strength is an important feature for the selection of dielectric materials, especially in high voltage engineering. Although nanocomposites have been shown to possess many promising dielectric properties, the breakdown strength of nanocomposites is often found to be negatively affected. Recently, imposing non-isothermal crystallization processes on polyethylene blends have been demonstrated to be favorable for breakdown strength improvements of dielectric materials. In an attempt to increase nanocomposites' voltage rating, the current work reports on the effects of non-isothermal crystallization (fast, moderate, and slow crystallizations) on the structure and dielectric properties of a polyethylene blend (PE) composed of $80 \%$ low density polyethylene and $20 \%$ high density polyethylene, added with silicon dioxide $\left(\mathrm{SiO}_{2}\right)$ and silicon nitride $\left(\mathrm{Si}_{3} \mathrm{~N}_{4}\right)$ nanofillers. Through breakdown testing, the breakdown performance of $\mathrm{Si}_{3} \mathrm{~N}_{4}$-based nanocomposites was better than $\mathrm{SiO}_{2}$-based nanocomposites. Since nanofiller dispersion within both nanocomposite systems was comparable, the enhanced breakdown performance of $\mathrm{Si}_{3} \mathrm{~N}_{4-}$ based nanocomposites is attributed to the surface chemistry of $\mathrm{Si}_{3} \mathrm{~N}_{4}$ containing less hydroxyl groups than $\mathrm{SiO}_{2}$. Furthermore, the breakdown strength of $\mathrm{SiO}_{2}$-based nanocomposites and $\mathrm{Si}_{3} \mathrm{~N}_{4-}$ based nanocomposites improved, with the DC breakdown strength increased by at least $12 \%$ when both the nanocomposites were subjected to moderate crystallization rather than fast and slow crystallizations. This is attributed to changes in the underlying molecular conformation of PE in addition to water-related effects. These results suggest that, apart from changes in the nanofiller surface chemistry, changes in the underlying molecular conformation of polymers are also important to improve the breakdown performance of nanocomposites.
\end{abstract}

Keywords: Nanocomposites, silicon dioxide, silicon nitride, polyethylene, crystallization, breakdown.

\section{Introduction}

Investigations of polymer nanocomposites as high voltage dielectric materials have increased tremendously over the last two decades. Since the introduction of the concept of dielectric nanocomposites, various nanocomposite materials have been explored, and these materials have been shown to possess promising dielectric properties such as those related to permittivity, partial discharge, space charge, and breakdown strength. ${ }^{1-4}$ For example, Nelson et al. ${ }^{5}$ 
discovered mitigated space charge accumulation and enhanced charge decay in epoxy/titania nanocomposites, which could lead to improved breakdown strength of the nanocomposites. Meanwhile, Okozumi et al. ${ }^{6}$ found that the volume resistivity and the breakdown strength of polyethylene nanocomposites increased with the addition of magnesium oxide nanofiller. These improved dielectric behaviors of nanocomposites have often been attributed to the appropriate use and good dispersion of nanoparticles, in addition to favorable nanoparticle/polymer interactions. ${ }^{7,8}$ These are much related to the presence of the interface within nanocomposites. ${ }^{9}$

In any dielectric, breakdown strength is an important dielectric parameter that determines the maximum electric field magnitude that the dielectric can withstand without failure. It is commonly expressed by the maximum voltage before failure divided by the thickness of the dielectric. Although the breakdown strength of polymers can be improved with the addition of nanoparticles to polymers, the breakdown properties can otherwise become inferior if interfacial mechanisms within nanocomposites are not properly dealt with. For example, reduced breakdown strength of polyethylene was reported with the addition of silicon dioxide $\left(\mathrm{SiO}_{2}\right)$, silicon nitride $\left(\mathrm{Si}_{3} \mathrm{~N}_{4}\right)$, and aluminum nitride (AlN) nanoparticles to polyethylene under ambient conditions. ${ }^{10}$ This is mainly caused by the presence of moisture on the surface of nanofillers, which subsequently resides on the interface of nanocomposites, thus leading to inferior dielectric properties. ${ }^{11,12}$ Meanwhile, the breakdown strength can also decrease with increasing amounts of nanoparticles due to nanoparticles agglomeration effects. ${ }^{13-15}$ These negative breakdown effects indicate that the addition of nanoparticles to polymers may not always enhance the breakdown strength of the materials, and that fundamental challenges regarding the breakdown behaviors of nanocomposites need to be addressed.

According to Green and Vaughan ${ }^{16}$, dielectric mechanisms of nanocomposites require exploration into various factors, which include nanoparticle dispersion, nanoparticle/polymer interactions, interactions between nanoparticles, properties of the base polymer, and molecular conformations. Significantly, an in-depth understanding of the underlying physics and chemistry governing changes in dielectric properties of nanocomposites needs to be sought after. To date, many research works on nanocomposites attempt to explain the mechanisms of nanocomposites through the use of single polymers as the matrices for nanocomposites. Nevertheless, Hosier et al. ${ }^{17,18}$ demonstrated that the use of a polyethylene blend system had many advantages over a single polymer system. The breakdown strength of a polyethylene blend composed of $80 \%$ low density polyethylene (LDPE) and 20\% high density polyethylene (HDPE) was reported to be the highest when the material was isothermally crystallized at 115 ${ }^{\circ} \mathrm{C} .{ }^{17}$ This was attributed to the open banded spherulitic structures composed of extensive isothermal lamellae (HDPE-rich phase) that were separated from each other by regions of quenched matrix (LDPE-rich phase). In addition, recent research work indicated that the use of polyethylene blend composed of $80 \%$ LDPE and $20 \%$ HDPE as the base polymer for nanocomposites allowed the control of the underlying polymer morphology. ${ }^{19,20}$ This enabled structural changes of the base polymer to be readily detected, provided that the material was appropriately crystallized.

It is noteworthy that crystallization is a process by which, upon cooling, nuclei (crystalline), an ordered solid phase, is produced from a liquid melt, wherein small regions of the tangled and random molecular conformations become ordered and aligned in the manner of chain-folded layers. There are mainly two types of crystallizations, namely, isothermal and nonisothermal crystallizations. Generally, studies of crystallization are limited to idealized conditions, in which external conditions are constant. For example, in the work Lau et al ${ }^{19,20}$, isothermal crystallization of the materials was achieved by contacting the materials with an external oil bath at fixed temperatures. In real situations, however, non-isothermal crystallization conditions are more common, in which the external conditions (e.g., cooling rates) change continuously. This is of greater interest since industrial processes proceed generally under non-isothermal conditions. Moreover, according to Lorenzo and Silvestre ${ }^{21}$, the study of crystallization in dynamic conditions may expand the general understanding of the crystallization behavior of polymers since many isothermal methods are often restricted to narrow temperature ranges. 
In this regard, Green et al. $^{22}$ considered a polyethylene blend produced using non-isothermal crystallization as a function of cooling rate. From the analysis, a non-isothermal cooling rate range window between $0.5^{\circ} \mathrm{C} \min ^{-1}$ and $10^{\circ} \mathrm{C} \min ^{-1}$ was estimated to correspond to the isothermal temperature window between $113{ }^{\circ} \mathrm{C}$ and $119{ }^{\circ} \mathrm{C}$, albeit that the morphologies of the resulting materials were different under non-isothermal and isothermal crystallization conditions. Morphological wise, at the cooling rate of $0.1{ }^{\circ} \mathrm{C} \mathrm{min}{ }^{-1}$, clear sheaf-like entities can be observed; by $10^{\circ} \mathrm{C} \mathrm{min}^{-1}$, the structure has given way to a more granular morphology. Their results showed that samples subjected to non-isothermal crystallization were found to possess higher breakdown strength compared to samples not subjected to crystallization. Recently, Hosier et al. ${ }^{23}$ found that the use of a nonisothermally crystallized polyethylene blend resulted in higher melting temperatures, reduced electrical conductivity, better space charge performance, increased electrical breakdown strength, and enhanced thermo-mechanical stability compared to conventionally crosslinked single polyethylene system. These benefits, yielded from non-isothermal crystallization of the material, indicate that more electrical power can be transmitted through the same size of a dielectric.

The aforementioned literature suggests that, to increase the voltage rating of a dielectric, the use of non-isothermal crystallization processes in the presence of nanofillers may create unique properties associated not only with the multiphase materials (polyethylene blend), but also with the interface resulted from nanoinclusions. The current work therefore aimed to explore the underlying physics and chemistry governing changes in dielectric properties of nanocomposites through non-isothermal crystallization processes of silicon-based polyethylene nanocomposites. A polyethylene blend, which enables the control of the material morphology through thermal treatment and possesses desirable breakdown properties that is independent of nucleation effects caused by nanofillers ${ }^{10}$, was selected as the base matrix. Meanwhile, silicon-based nanofillers, namely, silicon dioxide $\left(\mathrm{SiO}_{2}\right)$ and silicon nitride $\left(\mathrm{Si}_{3} \mathrm{~N}_{4}\right)$, were chosen as the nanofillers. The rationale behind the choice of $\mathrm{SiO}_{2}$ and $\mathrm{Si}_{3} \mathrm{~N}_{4}$ is that, $\mathrm{Si}_{3} \mathrm{~N}_{4}$ generally contains less water molecules than $\mathrm{SiO}_{2}$, where water-related effects seen in $\mathrm{SiO}_{2}$-based nanocomposites are less pronounced in $\mathrm{Si}_{3} \mathrm{~N}_{4}$-based nanocomposites ${ }^{24}$, such that nonisothermal crystallization processes of the two nanocomposite systems could be effectively compared.

\section{Experimental}

\subsection{Materials and Sample Preparation}

The base polymer used was a polyethylene blend (PE) composed of $80 \%$ LDPE (Titanlene LDF200YZ) and 20\% HDPE (Titanzex HI2000), sourced from Lotte Chemical. The nanofillers used were $\mathrm{SiO}_{2}$ nanopowder $(20 \mathrm{~nm})$ and $\mathrm{Si}_{3} \mathrm{~N}_{4}$ nanopowder $(15-30 \mathrm{~nm})$, sourced from NanoAmor.

By using a Brabender mixer, PE was mixed with the desired amount (1 wt $\%$ and $5 \mathrm{wt} \%$ ) of $\mathrm{SiO}_{2}$ and $\mathrm{Si}_{3} \mathrm{~N}_{4}$ at a temperature of $160{ }^{\circ} \mathrm{C}$ and a rotational speed of $45 \mathrm{rpm}$ for $10 \mathrm{~min}$. Thin film samples ( $100 \mu \mathrm{m}$ thick) were produced by melt-pressing through a hydraulic laboratory press at $160{ }^{\circ} \mathrm{C}$, with the samples sandwiched between two opposing Melinex films and metal plates. Later, each thin film sample was crystallized nonisothermally under fast, moderate, and slow crystallizations.

After crystallization, the thin film samples were carefully removed from the Melinex films for characterization purposes. For convenience, the notation $\mathrm{P} / \mathrm{F}-\mathrm{A} / \mathrm{C}$ is used to indicate the prepared samples, where $\mathrm{P}$ corresponds to the polymer, $\mathrm{F}$ represents the filler, A indicates the amount of filler, and $\mathrm{C}$ signifies the cooling condition, as shown in Table 1.

Table 1. Sample designation

\begin{tabular}{lcccc}
\hline $\begin{array}{l}\text { Sample } \\
\text { Designation } \\
(\mathbf{P} / \mathbf{F}-A / \mathbf{C})\end{array}$ & $\begin{array}{c}\text { Polymer } \\
(\mathbf{P})\end{array}$ & $\begin{array}{c}\text { Filler } \\
(\mathbf{F})\end{array}$ & $\begin{array}{c}\text { Amount } \\
(\mathbf{A})\end{array}$ & $\begin{array}{c}\text { Cooling } \\
\text { Condition } \\
(\mathbf{C})\end{array}$ \\
\hline $\mathrm{PE} / \mathrm{SiO}_{2}-1 / \mathrm{F}$ & $\mathrm{PE}$ & $\mathrm{SiO}_{2}$ & $1 \mathrm{wt} \%$ & Fast \\
$\mathrm{PE} / \mathrm{SiO}_{2}-5 / \mathrm{F}$ & $\mathrm{PE}$ & $\mathrm{SiO}_{2}$ & $5 \mathrm{wt} \%$ & Fast \\
$\mathrm{PE} / \mathrm{Si}_{3} \mathrm{~N}_{4}-1 / \mathrm{F}$ & $\mathrm{PE}$ & $\mathrm{Si}_{3} \mathrm{~N}_{4}$ & $1 \mathrm{wt} \%$ & Fast \\
$\mathrm{PE} / \mathrm{Si}_{3} \mathrm{~N}_{4}-5 / \mathrm{F}$ & $\mathrm{PE}$ & $\mathrm{Si}_{3} \mathrm{~N}_{4}$ & $5 \mathrm{wt} \%$ & Fast \\
$\mathrm{PE} / \mathrm{SiO}_{2}-1 / \mathrm{M}$ & $\mathrm{PE}$ & $\mathrm{SiO}_{2}$ & $1 \mathrm{wt} \%$ & Moderate \\
$\mathrm{PE} / \mathrm{SiO}_{2}-5 / \mathrm{M}$ & $\mathrm{PE}$ & $\mathrm{SiO}_{2}$ & $5 \mathrm{wt} \%$ & Moderate \\
$\mathrm{PE} / \mathrm{Si}_{3} \mathrm{~N}_{4}-1 / \mathrm{M}$ & $\mathrm{PE}$ & $\mathrm{Si}_{3} \mathrm{~N}_{4}$ & $1 \mathrm{wt} \%$ & Moderate \\
$\mathrm{PE} / \mathrm{Si}_{3} \mathrm{~N}_{4}-5 / \mathrm{M}$ & $\mathrm{PE}$ & $\mathrm{Si}_{3} \mathrm{~N}_{4}$ & $5 \mathrm{wt} \%$ & Moderate \\
$\mathrm{PE} / \mathrm{SiO}_{2}-1 / \mathrm{S}$ & $\mathrm{PE}$ & $\mathrm{SiO}_{2}$ & $1 \mathrm{wt} \%$ & Slow \\
$\mathrm{PE} / \mathrm{SiO}_{2}-5 / \mathrm{S}$ & $\mathrm{PE}$ & $\mathrm{SiO}_{2}$ & $5 \mathrm{wt} \%$ & Slow \\
$\mathrm{PE} / \mathrm{Si}_{3} \mathrm{~N}_{4}-1 / \mathrm{S}$ & $\mathrm{PE}$ & $\mathrm{Si}_{3} \mathrm{~N}_{4}$ & $1 \mathrm{wt} \%$ & Slow \\
$\mathrm{PE} / \mathrm{Si}_{3} \mathrm{~N}_{4}-5 / \mathrm{S}$ & $\mathrm{PE}$ & $\mathrm{Si}_{3} \mathrm{~N}_{4}$ & $5 \mathrm{wt} \%$ & Slow \\
\hline
\end{tabular}




\subsection{Characterization}

The cooling rate of experimentally crystallized samples under fast, moderate, and slow crystallizations was determined using a Fluke 52II digital thermometer. A Perkin Elmer differential scanning calorimeter (DSC) with Pyris software was used to characterize the thermal behavior of the experimentally crystallized samples. For each measurement, a $5 \mathrm{mg}$ sample was used, placed in a sealed aluminum pan. The measurement was carried out under nitrogen atmosphere with a temperature range from $30{ }^{\circ} \mathrm{C}$ to $160{ }^{\circ} \mathrm{C}$ at $10{ }^{\circ} \mathrm{C} \mathrm{min}{ }^{-1}$ scan rate. Overall, an accuracy of $\pm 1{ }^{\circ} \mathrm{C}$ in temperature and $\pm 3 \%$ in enthalpy was estimated based upon repeated measurements from a similar set of samples.

The melting enthalpy for each material was analyzed and converted into the percentage of LDPE or HDPE present in nanocomposites that was involved in each phase transition. ${ }^{25}$ The degree of crystallinity $(\chi)$ of each material was then obtained by dividing the enthalpy normalized by weight with the enthalpy of $100 \%$ crystalline material, taken as $293 \mathrm{Jg}^{-1}$ for polyethylene ${ }^{26,27}$, as follow:

$$
\chi=\frac{\Delta H}{w_{f} \Delta H_{\mathrm{o}}} \times 100
$$

where $\Delta H$ is the melting enthalpy of the sample, $\Delta H_{\circ}$ is the value of enthalpy corresponding to the melting of a $100 \%$ crystalline material and $w_{f}$ is the weight fraction of the crystallizable material.

A Perkin Elmer Spectrum One spectrometer with a standard temperature-stabilized mid-infrared triglycine sulfate (MIRTGS) detector was used to collect the Fourier transform infrared (FTIR) spectra of $\mathrm{SiO}_{2}$ and $\mathrm{Si}_{3} \mathrm{~N}_{4}$ nanopowders. The FTIR spectra of $\mathrm{SiO}_{2}$-based nanocomposites and $\mathrm{Si}_{3} \mathrm{~N}_{4}$-based nanocomposites were also collected using the same instrument. The spectrum for each data was collected from $400 \mathrm{~cm}^{-1}$ to $4000 \mathrm{~cm}^{-1}$ over 16 scans at $4 \mathrm{~cm}^{-1}$ resolution.

The morphology of the samples was characterized using JEOL JSM-6390 LV and Hitachi TM3000 Tabletop scanning electron microscopes (SEM). An accelerating voltage of $15 \mathrm{kV}$ was used. Prior to SEM, the samples were fractured under liquid nitrogen and sputter coated with gold or platinum.

Electrical breakdown testing was conducted in line with ASTM D149, by placing each sample between two
$6.3 \mathrm{~mm}$ diameter steel ball electrodes immersed in mineral oil. For AC breakdown testing, a step voltage of $1 \mathrm{kV}$ every $20 \mathrm{~s}$ was applied until breakdown occurred. For DC breakdown testing, a step voltage of $2 \mathrm{kV}$ every $20 \mathrm{~s}$ was applied until breakdown occurred. Fifteen breakdown tests were conducted on each type of samples. The resulting data were analyzed using twoparameter Weibull statistics ${ }^{28,29}$ :

$$
P(x)=1-\exp \left[-\left(\frac{E}{\alpha}\right)^{\beta}\right]
$$

where $P(x)$ is the cumulative failure probability at $E$, $E$ is the experimental electric field $\left(\mathrm{kV} \mathrm{mm}^{-1}\right), \alpha$ is the scale parameter $\left(\mathrm{kV} \mathrm{mm}^{-1}\right)$ representing the breakdown strength at $63.2 \%$ probability, and $\beta$ is the shape parameter reflecting the data distribution.

\section{Results and Discussion}

\subsection{Cooling Rates and Melting Behaviors}

The representative data for measuring the cooling rates of nanocomposites containing $\mathrm{SiO}_{2}$ and $\mathrm{Si}_{3} \mathrm{~N}_{4}$ are shown in Figures 1a (fast crystallization), $1 \mathrm{~b}$ (moderate crystallization), and 1c (slow crystallization). Under a linear temperature-time relationship, the cooling rates of the experimentally crystallized samples under fast, moderate, and slow crystallizations were approximately $80{ }^{\circ} \mathrm{C} \mathrm{min}^{-1}\left(1.28{ }^{\circ} \mathrm{C} \mathrm{s}^{-1}\right), 15^{\circ} \mathrm{C} \mathrm{min}^{-1}\left(0.25^{\circ} \mathrm{C} \mathrm{s}^{-1}\right)$, and 1 ${ }^{\circ} \mathrm{C} \mathrm{min}^{-1}\left(0.02{ }^{\circ} \mathrm{C} \mathrm{s}^{-1}\right)$, respectively.

Figure 2 shows the representative melting thermograms of nanocomposites containing $1 \mathrm{wt} \%$ of $\mathrm{SiO}_{2}$ and $\mathrm{Si}_{3} \mathrm{~N}_{4}$; similar melting thermograms were obtained from nanocomposites containing $5 \mathrm{wt} \%$ of $\mathrm{SiO}_{2}$ and $\mathrm{Si}_{3} \mathrm{~N}_{4}$, hence not shown for brevity. The lower peak melting temperature (denoted as $T_{m 1}$ ) at about 107 ${ }^{\circ} \mathrm{C}$ is close to the melting temperature of the LDPE and is therefore associated with lamellae composed mainly of branched molecules. Meanwhile, the upper peak melting temperature (denoted as $T_{m 2}$ ) at about $126^{\circ} \mathrm{C}$ is close to the melting temperature of the HDPE and is therefore associated with lamellae composed mainly of linear HDPE molecules. These melting behaviors reflect that of a polyethylene blend, and are in line with published literature. ${ }^{17,18,30,31}$

As the cooling rate increased, an additional peak melting temperature (denoted as $T_{m x}$ ) appeared and became more pronounced; the melting features of $T_{m I}$ 


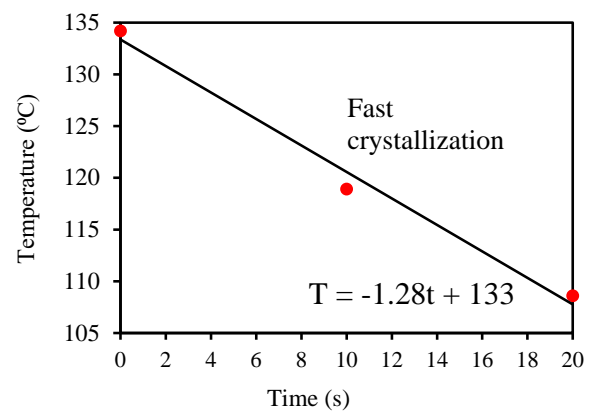

(a)

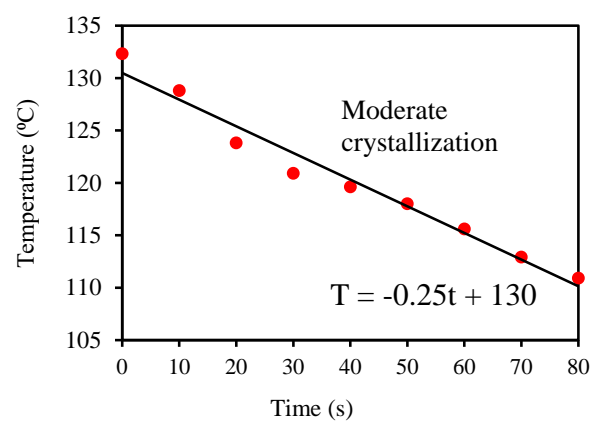

(b)

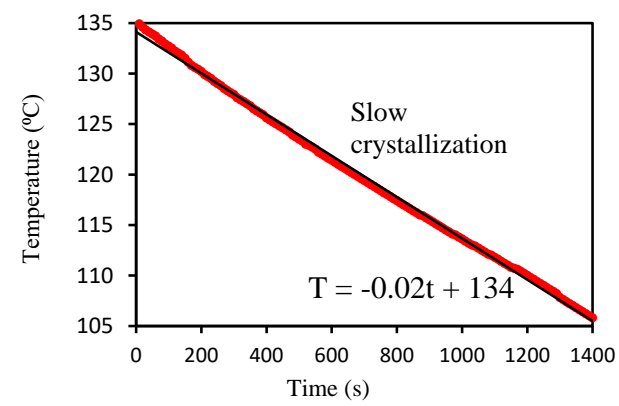

(c)

Fig. 1. Experimentally measured cooling rates under (a) fast, (b) moderate, (c) slow crystallization conditions

and $T_{m 2}$ generally remained unchanged. The multiple melting peaks associated with $T_{m 2}$ and $T_{m x}$ can be related to molecular fractionation, co-crystallization, and dynamic reorganization of crystals. ${ }^{17,31}$ The peak of $T_{m x}$ was about $122{ }^{\circ} \mathrm{C}$ under fast crystallization, and increased to $125{ }^{\circ} \mathrm{C}$ under moderate crystallization; $T_{m x}$ was not present under slow crystallization.

Table 2 summarizes the melting temperatures for all nanocomposites under fast, moderate, and slow crystallizations. From these thermal analyses, there were no appreciable differences between $\mathrm{PE} / \mathrm{SiO}_{2}$ and $\mathrm{PE} / \mathrm{Si}_{3} \mathrm{~N}_{4}$ nanocomposites. The similar melting behaviors of the two nanocomposite systems indicate that, for any given crystallization condition, the thickness of the lamellae was similar irrespective of the type and amount of nanofillers.

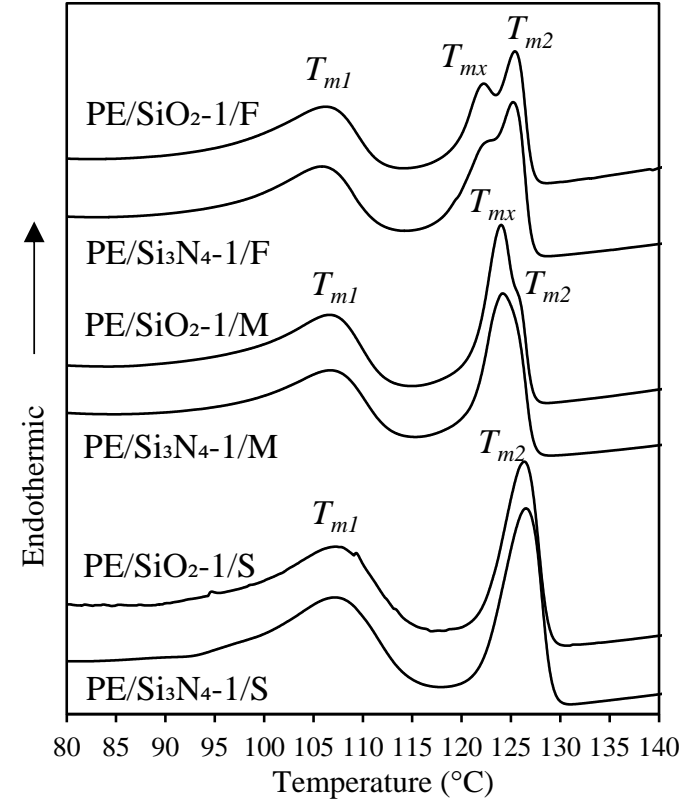

Fig. 2. Melting thermograms of nanocomposites containing $1 \mathrm{wt} \%$ of $\mathrm{SiO}_{2}$ and $\mathrm{Si}_{3} \mathrm{~N}_{4}$, when subjected to fast, moderate and slow crystallizations

Table 2. Melting temperature data obtained from DSC

\begin{tabular}{lccc}
\hline \multirow{2}{*}{ Sample } & \multicolumn{3}{c}{ Melting Temperature, $\mathbf{T}_{\mathbf{m}}$} \\
& $\mathbf{T}_{\mathbf{m} 1}\left({ }^{\mathbf{0}} \mathbf{C}\right)$ & $\mathbf{T}_{\mathbf{m} 2}\left({ }^{\mathbf{0}} \mathbf{C}\right)$ & $\mathbf{T}_{\mathbf{m x}}\left({ }^{\mathbf{}} \mathbf{C}\right)$ \\
\hline $\mathrm{PE} / \mathrm{SiO}_{2}-1 / \mathrm{F}$ & 107 & 127 & 122 \\
$\mathrm{PE} / \mathrm{SiO}_{2}-5 / \mathrm{F}$ & 108 & 127 & 123 \\
$\mathrm{PE} / \mathrm{Si}_{3} \mathrm{~N}_{4}-1 / \mathrm{F}$ & 107 & 126 & 122 \\
$\mathrm{PE} / \mathrm{Si}_{3} \mathrm{~N}_{4}-5 / \mathrm{F}$ & 107 & 126 & 120 \\
$\mathrm{PE} / \mathrm{SiO}_{2}-1 / \mathrm{M}$ & 107 & 127 & 125 \\
$\mathrm{PE} / \mathrm{SiO}_{2}-5 / \mathrm{M}$ & 108 & 126 & 125 \\
$\mathrm{PE} / \mathrm{Si}_{3} \mathrm{~N}_{4}-1 / \mathrm{M}$ & 108 & 127 & 125 \\
$\mathrm{PE} / \mathrm{Si}_{3} \mathrm{~N}_{4}-5 / \mathrm{M}$ & 107 & 127 & 125 \\
$\mathrm{PE} / \mathrm{SiO}_{2}-1 / \mathrm{S}$ & 108 & 128 & - \\
$\mathrm{PE} / \mathrm{SiO}_{2}-5 / \mathrm{S}$ & 108 & 127 & - \\
$\mathrm{PE} / \mathrm{Si}_{3} \mathrm{~N}_{4}-1 / \mathrm{S}$ & 108 & 127 & - \\
$\mathrm{PE} / \mathrm{Si}_{3} \mathrm{~N}_{4}-5 / \mathrm{S}$ & 108 & 127 & - \\
\hline
\end{tabular}

\subsection{Crystallinity Analysis}

Table 3 summarizes the data for the melting enthalpy $(\Delta H)$ and degree of crystallinity $(\chi)$ of nanocomposites containing $1 \mathrm{wt} \%$ and $5 \mathrm{wt} \%$ of $\mathrm{SiO}_{2}$ and $\mathrm{Si}_{3} \mathrm{~N}_{4}$. Since the base matrix was composed of a blend of LDPE and HDPE, and the DSC thermal traces were largely divided into these two phases, with one phase dominated by $T_{m 1}$ (representing the LDPE-rich phase) while the other phase dominated by $T_{m 2}$ and/or $T_{m x}$ (representing the HDPE-rich phase), the crystallinity of the materials was therefore analyzed based on the LDPE-rich phase and the HDPE-rich phase. 
Table 3. Crystallinity of LDPE-rich phase and HDPE-rich phase

\begin{tabular}{lcccc}
\hline \multirow{2}{*}{ Sample } & \multicolumn{2}{c}{ LDPE-rich phase } & \multicolumn{2}{c}{ HDPE-rich phase } \\
& $\Delta \boldsymbol{H}\left(\mathbf{J g}^{-1}\right)$ & $\boldsymbol{\chi}(\boldsymbol{\%})$ & $\Delta \boldsymbol{H}\left(\mathbf{J g}^{-1}\right)$ & $\boldsymbol{\chi}(\boldsymbol{\%})$ \\
\hline $\mathrm{PE} / \mathrm{SiO}_{2}-1 / \mathrm{F}$ & 14.3 & 6.2 & 25.2 & 43.4 \\
$\mathrm{PE} / \mathrm{SiO}_{2}-5 / \mathrm{F}$ & 15.2 & 6.8 & 24.2 & 43.5 \\
$\mathrm{PE} / \mathrm{Si}_{3} \mathrm{~N}_{4}-1 / \mathrm{F}$ & 13.9 & 6.0 & 26.9 & 46.4 \\
$\mathrm{PE} / \mathrm{Si}_{3} \mathrm{~N}_{4}-5 / \mathrm{F}$ & 11.8 & 5.3 & 27.0 & 48.6 \\
$\mathrm{PE} / \mathrm{SiO}_{2}-1 / \mathrm{M}$ & 14.6 & 6.3 & 26.6 & 45.9 \\
$\mathrm{PE} / \mathrm{SiO}_{2}-5 / \mathrm{M}$ & 15.7 & 7.0 & 25.8 & 46.3 \\
$\mathrm{PE} / \mathrm{Si}_{3} \mathrm{~N}_{4}-1 / \mathrm{M}$ & 14.3 & 6.2 & 27.9 & 48.2 \\
$\mathrm{PE} / \mathrm{Si}_{3} \mathrm{~N}_{4}-5 / \mathrm{M}$ & 11.9 & 5.3 & 28.4 & 51.0 \\
$\mathrm{PE} / \mathrm{SiO}_{2}-1 / \mathrm{S}$ & 14.2 & 6.1 & 24.8 & 42.7 \\
$\mathrm{PE} / \mathrm{SiO}_{2}-5 / \mathrm{S}$ & 14.8 & 6.7 & 23.9 & 42.9 \\
$\mathrm{PE} / \mathrm{Si}_{3} \mathrm{~N}_{4}-1 / \mathrm{S}$ & 14.2 & 6.1 & 26.8 & 46.2 \\
$\mathrm{PE} / \mathrm{Si}_{3} \mathrm{~N}_{4}-5 / \mathrm{S}$ & 11.7 & 5.2 & 27.3 & 49.0 \\
\hline
\end{tabular}

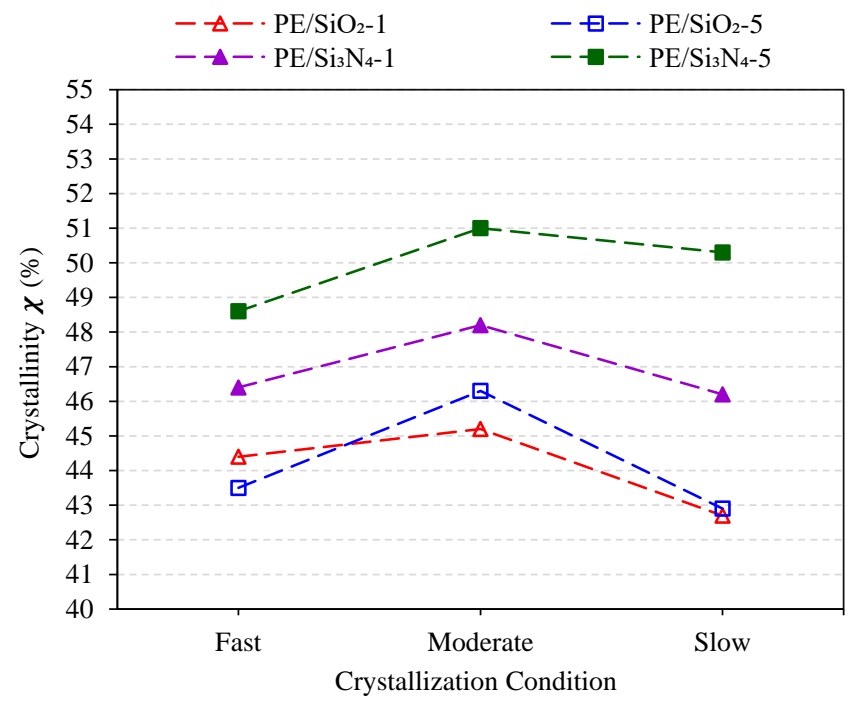

Fig. 3. Crystallinity of HDPE-rich phase for nanocomposites under fast, moderate and slow crystallizations

For all the materials, the crystallinity of the LDPErich phase appears similar when taking into account the uncertainties in the analysis. Therefore, crystallizing the materials under fast, moderate, and slow crystallizations did not affect the crystallinity of the LDPE-rich phase.

Although it appears that, under each crystallization condition, the crystallinity of the HDPE-rich phase of $\mathrm{PE} / \mathrm{Si}_{3} \mathrm{~N}_{4}$ nanocomposites was higher than $\mathrm{PE} / \mathrm{SiO}_{2}$ nanocomposites, these differences lie within the uncertainties of the analysis, hence not reproducible. Rather, crystallinity analysis of the HDPE-rich phase among samples under fast, moderate, and slow crystallizations reveals appreciable differences, where the crystallinity was the highest under moderate crystallization compared to slow and fast crystallizations. This trend is largely reproducible for each material; the crystallinity of the materials under fast and slow crystallizations was largely indistinguishable. This is better illustrated in Figure 3. This suggests that the use of different non-isothermal crystallization conditions had a notable effect on the melting behaviors of the materials (where the aforementioned "double peak" feature became more pronounced with increased cooling rates), thus affecting the crystallization kinetics and the underlying lamellar structure of the base PE.

\subsection{Chemical Structure}

Figure 4 shows the FTIR spectra of the $\mathrm{SiO}_{2}$ and $\mathrm{Si}_{3} \mathrm{~N}_{4}$ nanopowders. For the $\mathrm{SiO}_{2}$ nanopowder, characteristic absorption bands were observed at $1088 \mathrm{~cm}^{-1}, 800 \mathrm{~cm}^{-1}$ and $470 \mathrm{~cm}^{-1}$, and they belong to Si-O bonds. ${ }^{32}$ Meanwhile, characteristic absorption bands at $1084 \mathrm{~cm}^{-}$ ${ }^{1}, 960 \mathrm{~cm}^{-1,}$ and $470 \mathrm{~cm}^{-1}$ were observed for the $\mathrm{Si}_{3} \mathrm{~N}_{4}$ nanopowder, which depict the $\mathrm{Si}-\mathrm{O}$ and $\mathrm{Si}-\mathrm{N}$ bonds. ${ }^{33,34}$ Additionally, both the $\mathrm{SiO}_{2}$ and $\mathrm{Si}_{3} \mathrm{~N}_{4}$ nanopowders show a characteristic absorption band at $3400 \mathrm{~cm}^{-1}$, which can be attributed to surface hydroxyl groups and associated water molecules on the surface of the nanopowders. ${ }^{19}$ Of note, the intensity at $3400 \mathrm{~cm}^{-1}$ was much less for $\mathrm{Si}_{3} \mathrm{~N}_{4}$ than $\mathrm{SiO}_{2}$, indicating that the presence of water was much less on $\mathrm{Si}_{3} \mathrm{~N}_{4}$ nanopowder. Since $\mathrm{SiO}_{2}$ is prone to water adsorption, surface hydroxyl groups tend to be present on the surface of $\mathrm{SiO}_{2}$ when exposed to air or water surroundings. Indeed, available literature ${ }^{10,35}$ shows that $\mathrm{SiO}_{2}$ adsorbs a significant amount of water even when stored under ambient conditions, suggesting that water can readily be partitioned to polar $\mathrm{SiO}_{2}$ surfaces; $\mathrm{Si}_{3} \mathrm{~N}_{4}$ adsorbs little water compared to $\mathrm{SiO}_{2}$ under ambient conditions. Therefore, the water adsorption effects are much less pronounced for $\mathrm{Si}_{3} \mathrm{~N}_{4}$ compared to $\mathrm{SiO}_{2}$.

Figure 5 shows the FTIR spectra of nanocomposites containing $1 \mathrm{wt} \%$ and $5 \mathrm{wt} \%$ of $\mathrm{SiO}_{2}$ and $\mathrm{Si}_{3} \mathrm{~N}_{4}$ under fast, moderate, and slow crystallizations. Of note, the absorption bands at $2840-2928 \mathrm{~cm}^{-1}, 1465 \mathrm{~cm}^{-1}$, and 720 $\mathrm{cm}^{-1}$ are typical for polyethylene. ${ }^{36} \mathrm{By}$ adding $1 \mathrm{wt} \%$ of $\mathrm{SiO}_{2}$ to $\mathrm{PE}$, three additional absorption bands representing $\mathrm{SiO}_{2}$ nanopowder (as discussed in Figure 4) can be observed at $1088 \mathrm{~cm}^{-1}, 800 \mathrm{~cm}^{-1}$, and $470 \mathrm{~cm}^{-}$ 1 . By increasing the amount of $\mathrm{SiO}_{2}$ to $5 \mathrm{wt} \%$, these absorption bands became more pronounced. Meanwhile, adding $1 \mathrm{wt} \%$ of $\mathrm{Si}_{3} \mathrm{~N}_{4}$ to PE resulted in three absorption 


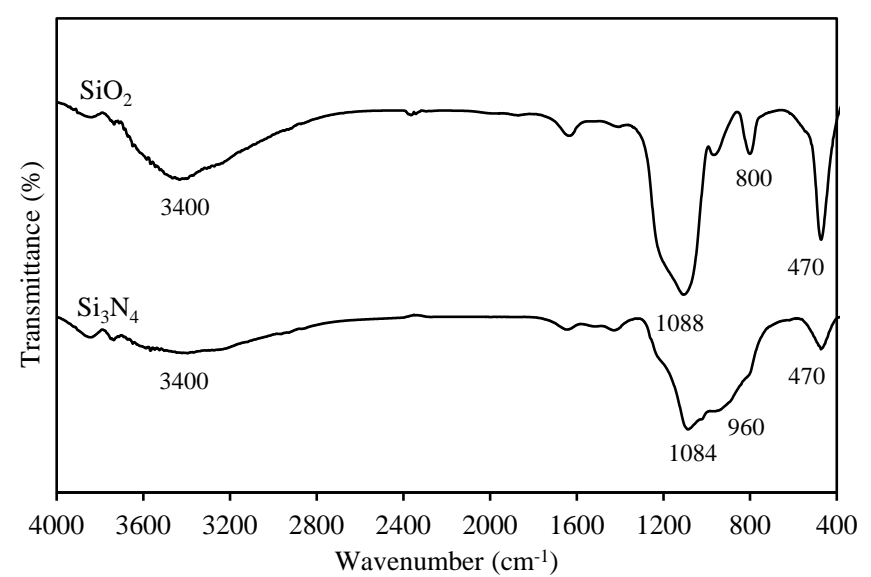

Fig. 4. FTIR spectra of $\mathrm{SiO}_{2}$ and $\mathrm{Si}_{3} \mathrm{~N}_{4}$ nanopowders

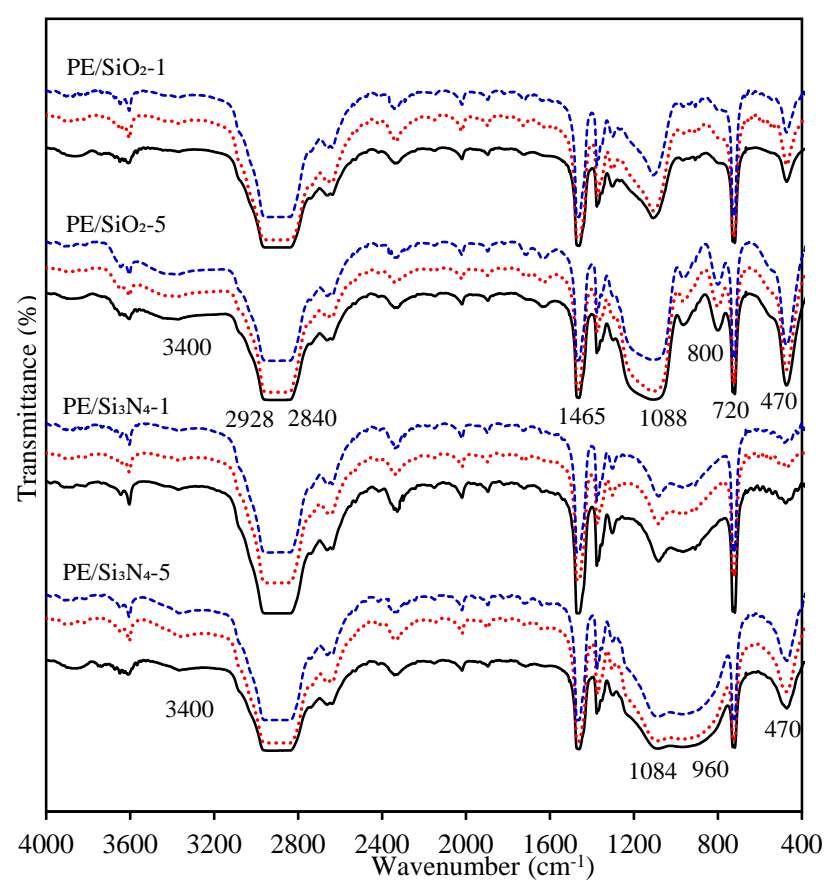

Fig. 5. FTIR spectra of nanocomposites containing $1 \mathrm{wt} \%$ and 5 wt $\%$ of $\mathrm{SiO}_{2}$ and $\mathrm{Si}_{3} \mathrm{~N}_{4}$ under fast, moderate, and slow crystallizations

bands at $1084 \mathrm{~cm}^{-1}, 960 \mathrm{~cm}^{-1}$, and $470 \mathrm{~cm}^{-1}$ representing $\mathrm{Si}_{3} \mathrm{~N}_{4}$ nanopowder (as discussed in Figure 4), and these absorption bands became more pronounced at $5 \mathrm{wt} \%$ $\mathrm{Si}_{3} \mathrm{~N}_{4}$. Again, a comparison of the FTIR spectra of $\mathrm{PE} / \mathrm{SiO}_{2}$ nanocomposites and $\mathrm{PE} / \mathrm{Si}_{3} \mathrm{~N}_{4}$ nanocomposites at $3400 \mathrm{~cm}^{-1}$ indicates that surface hydroxyl groups and associated water molecules were indeed more apparent in $\mathrm{SiO}_{2}$-based nanocomposites than in $\mathrm{Si}_{3} \mathrm{~N}_{4}$-based nanocomposites. Nevertheless, imposing different crystallization conditions on the nanocomposites did not result in notable changes on the chemical structure of the materials.

\subsection{SEM Morphology}

Figure 6 shows the SEM micrographshhhhh of $\mathrm{SiO}_{2}$ based nanocomposites. $\mathrm{SiO}_{2}$ nanoparticles of less than $100 \mathrm{~nm}$ can be observed from SEM micrographs of $\mathrm{PE} / \mathrm{SiO}_{2}-1 / \mathrm{F}, \quad \mathrm{PE} / \mathrm{SiO}_{2}-1 / \mathrm{M}, \quad$ and $\mathrm{PE} / \mathrm{SiO}_{2}-1 / \mathrm{S}$ (examples were circled in Figures 6a, 6b, and 6c, respectively). Increasing the $\mathrm{SiO}_{2}$ content to $5 \mathrm{wt} \%$ resulted in more numbers of fine particles in $\mathrm{PE} / \mathrm{SiO}_{2}-$ $5 / \mathrm{F}, \mathrm{PE} / \mathrm{SiO}_{2}-5 / \mathrm{M}$, and $\mathrm{PE} / \mathrm{SiO}_{2}-5 / \mathrm{S}$, as circled in Figures $6 \mathrm{~d}, 6 \mathrm{e}$, and $6 \mathrm{f}$, respectively. While the lamellar structure of the base PE can be observed in all micrographs (arrowed), it is somehow difficult to distinguish the lamellar network of the base PE subjected to fast, moderate, and slow crystallizations due to the presence of nanoparticles and image artefacts caused by the fracture surface of the samples, as explained elsewhere. ${ }^{37,38}$

Meanwhile, the presence of $1 \mathrm{wt} \%$ of $\mathrm{Si}_{3} \mathrm{~N}_{4}$ of less than $100 \mathrm{~nm}$ can be observed in Figures 7a, 7b, and 7c (examples were circled) for samples prepared under fast,

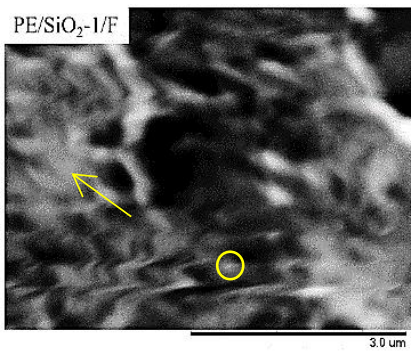

(a)

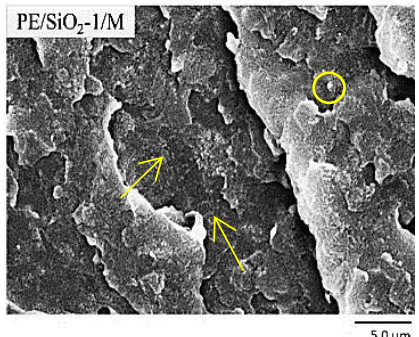

(b)

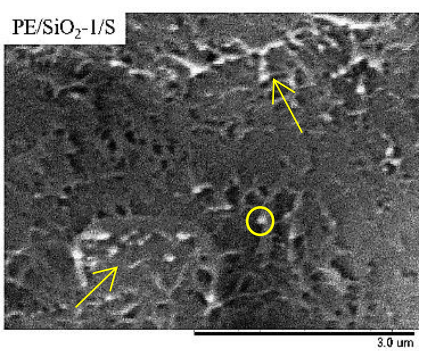

(c)

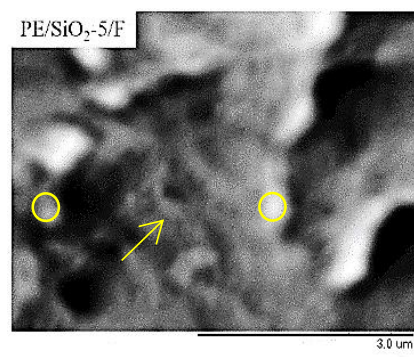

(d)

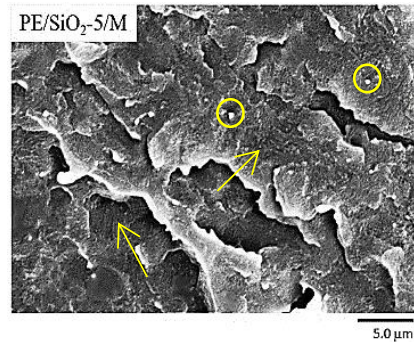

(e)

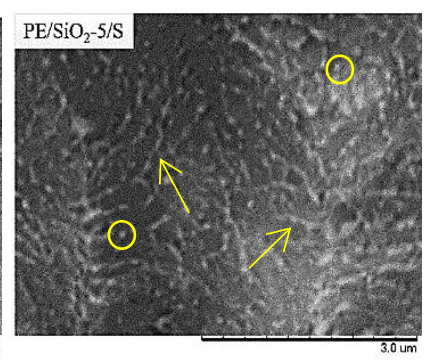

(f)
Fig. 6. Morphology of nanocomposites containing $1 \mathrm{wt} \%$ of $\mathrm{SiO}_{2}$ under (a) fast, (b) moderate, (c) slow crystallizations and nanocomposites containing $5 \mathrm{wt} \%$ of $\mathrm{SiO}_{2}$ under (d) fast, (e) moderate, (f) slow crystallizations 


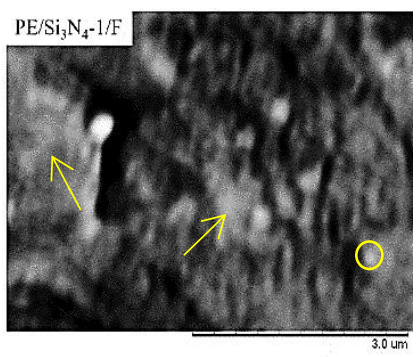

(a)

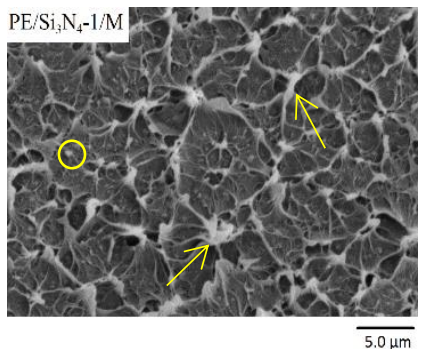

(b)

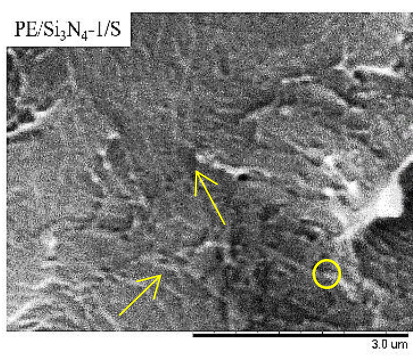

(c)

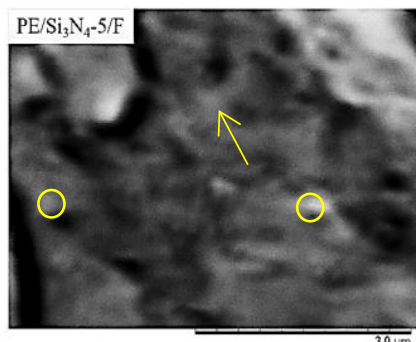

(d)

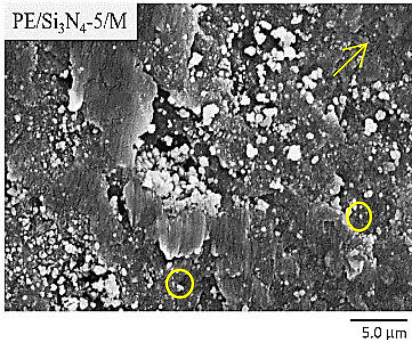

(e)

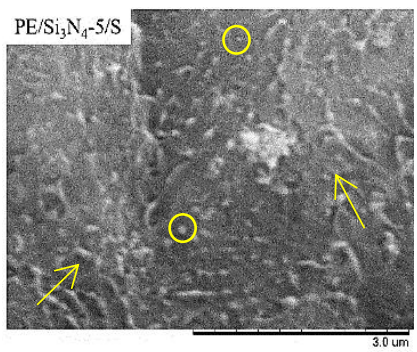

(f)
Fig. 7. Morphology of nanocomposites containing $1 \mathrm{wt} \%$ of $\mathrm{Si}_{3} \mathrm{~N}_{4}$ under (a) fast, (b) moderate, (c) slow crystallizations and nanocomposites containing $5 \mathrm{wt} \%$ of $\mathrm{Si}_{3} \mathrm{~N}_{4}$ under (d) fast, (e) moderate, (f) slow crystallizations

moderate, and slow crystallizations, respectively. Increasing the amount of $\mathrm{Si}_{3} \mathrm{~N}_{4}$ to $5 \mathrm{wt} \%$ resulted in the presence of more numbers of particle as shown in Figures $7 \mathrm{~d}, 7 \mathrm{e}$, and $7 \mathrm{f}$ (examples were circled), respectively. By analyzing Figures 6 and 7, changes on the underlying morphology of the base PE under fast, moderate, and slow crystallizations became better observed. Firstly, fast crystallization of the materials led to featureless lamellar structure of the materials (see the arrowed regions in Figures 6a, 6d, 7a, and 7d). Such a feature is somehow similar to that of a quenched polymer sample, where the texture of a quenched sample is often shown as a featureless region and less revealing under SEM and sometimes even under transmission electron microscopy. ${ }^{17,18}$ Secondly, moderate crystallization of the materials caused the lamellar arrangement to become granular-like (see the arrowed regions in Figures $6 \mathrm{~b}, 6 \mathrm{e}, 7 \mathrm{~b}$, and 7e). Lastly, slow crystallization of the materials led to coarser, sheaf-like lamellar arrangement (see the arrowed regions in Figures $6 \mathrm{c}, 6 \mathrm{f}, 7 \mathrm{c}$, and 7f). The granular-like morphology and sheaf-like morphology are comparable to the work as reported in the literature. ${ }^{22}$ It is noteworthy that single lamellar crystals and fine size nanoparticles were not well revealed in the current work, where the lamellar textures and the fine particles tend to obscure each other. While the use of the permanganic etching technique ${ }^{39}$ can be pursued such that the crystalline phase of the PE can be well distinguished from its amorphous phase, previous work ${ }^{20,32}$ suggests that revealing the complete lamellar and nanoparticle size distributions within a polyethylene blend nanocomposite system is challenging.

Of note, agglomeration of nanoparticles could not be completely avoided in the current work, and this is illustrated through a representative SEM micrograph of nanocomposites containing $5 \mathrm{wt} \%$ of $\mathrm{Si}_{3} \mathrm{~N}_{4}$ in Figure 7e. Similar issue was also found for $\mathrm{SiO}_{2}$-based nanocomposites (not shown for brevity). It is well known that nanoparticles commonly appear as agglomerates rather than isolated particles in nanocomposites, and agglomeration effects become more apparent with increasing amounts of nanoparticles. ${ }^{40}$ Of note, visual examination of a number of SEM micrographs of the nanocomposites suggests that the dispersion of an equivalent amount of $\mathrm{SiO}_{2}$ and $\mathrm{Si}_{3} \mathrm{~N}_{4}$ nanofillers in PE was comparable.

\subsection{Electrical Breakdown Strength}

Figure 8a shows the AC breakdown strength of $\mathrm{SiO}_{2}$ based nanocomposites under fast, moderate, and slow crystallizations. The highest AC breakdown strength $\left(163 \mathrm{kV} \mathrm{mm}^{-1}\right)$ was achieved with the material moderately crystallized $\left(\mathrm{PE} / \mathrm{SiO}_{2}-1 / \mathrm{M}\right)$. Increasing the amount of $\mathrm{SiO}_{2}$ to $5 \mathrm{wt} \%$ generally reduced the $\mathrm{AC}$ breakdown strength of the similar nanocomposite system (see Figure 8b). Nevertheless, the AC breakdown strength of the materials, when moderately crystallized ( $\left.\mathrm{PE} / \mathrm{SiO}_{2}-5 / \mathrm{M}\right)$, was again, the highest (132 $\mathrm{kV} \mathrm{mm}^{-1}$ ) compared to the same materials subjected to fast and slow crystallizations. Under the respective crystallization conditions, the AC breakdown strength of $\mathrm{PE} / \mathrm{Si}_{3} \mathrm{~N}_{4}$ nanocomposites was comparable to that of $\mathrm{PE} / \mathrm{SiO}_{2}$ nanocomposites under equivalent nanofiller loading levels. Prior work suggests that different types of nanofillers were less influential under AC fields. ${ }^{41}$ Of note, the AC breakdown strength of $\mathrm{Si}_{3} \mathrm{~N}_{4}$-based nanocomposites was, again, the highest under moderate crystallization under $1 \mathrm{wt} \%$ and $5 \mathrm{wt} \%$ of $\mathrm{Si}_{3} \mathrm{~N}_{4}$ loading levels. 
NANO: Brief Reports and Reviews

Vol. 1, No. 1 (2020) 9-13

(C) World Scientific Publishing Company
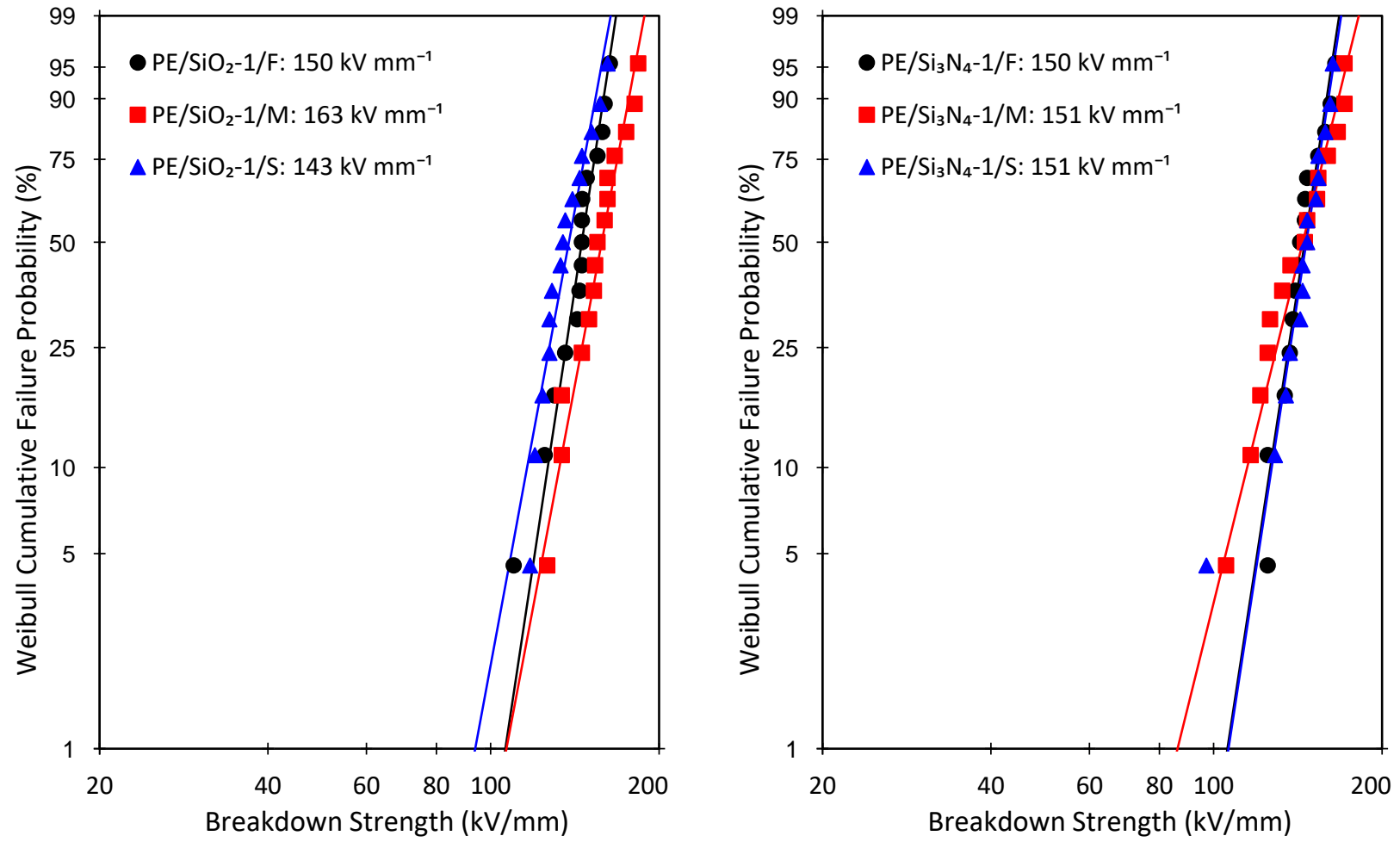

(a)

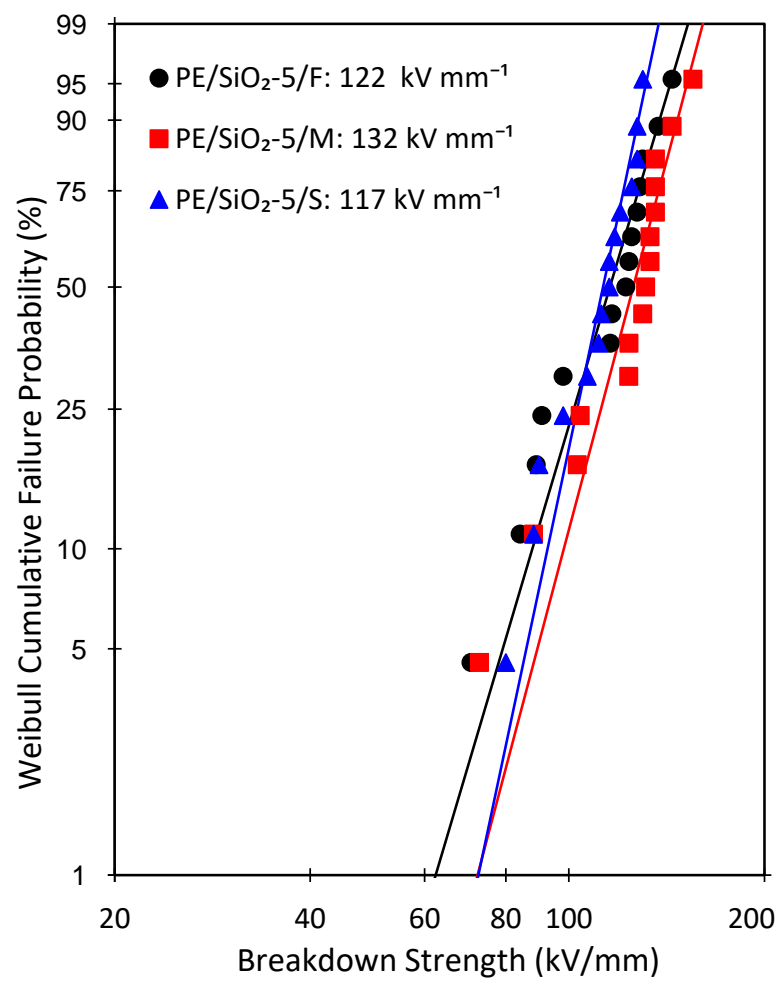

(b)

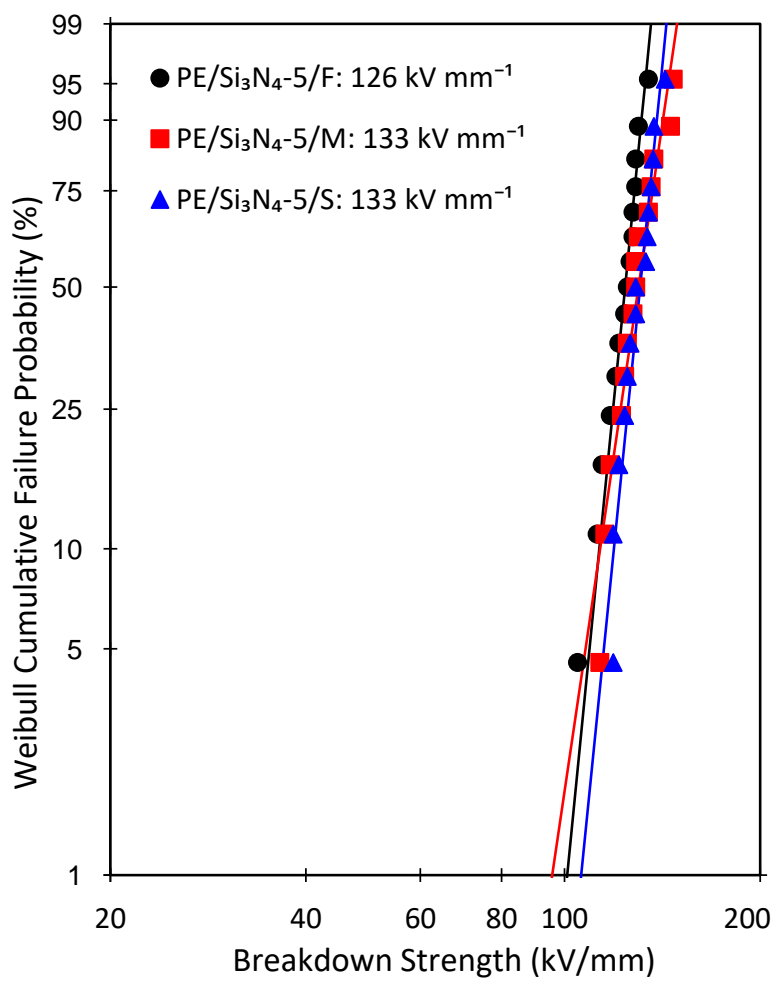

(d)

Fig. 8. Weibull plots comparing AC breakdown strength of nanocomposites containing (a) $1 \mathrm{wt} \%$ of $\mathrm{SiO}_{2}$, (b) $5 \mathrm{wt} \%$ of $\mathrm{SiO}_{2}$, (c) 1 wt $\%$ of $\mathrm{Si}_{3} \mathrm{~N}_{4}$, (d) $5 \mathrm{wt} \%$ of $\mathrm{Si}_{3} \mathrm{~N}_{4}$, under fast, moderate, and slow crystallizations 


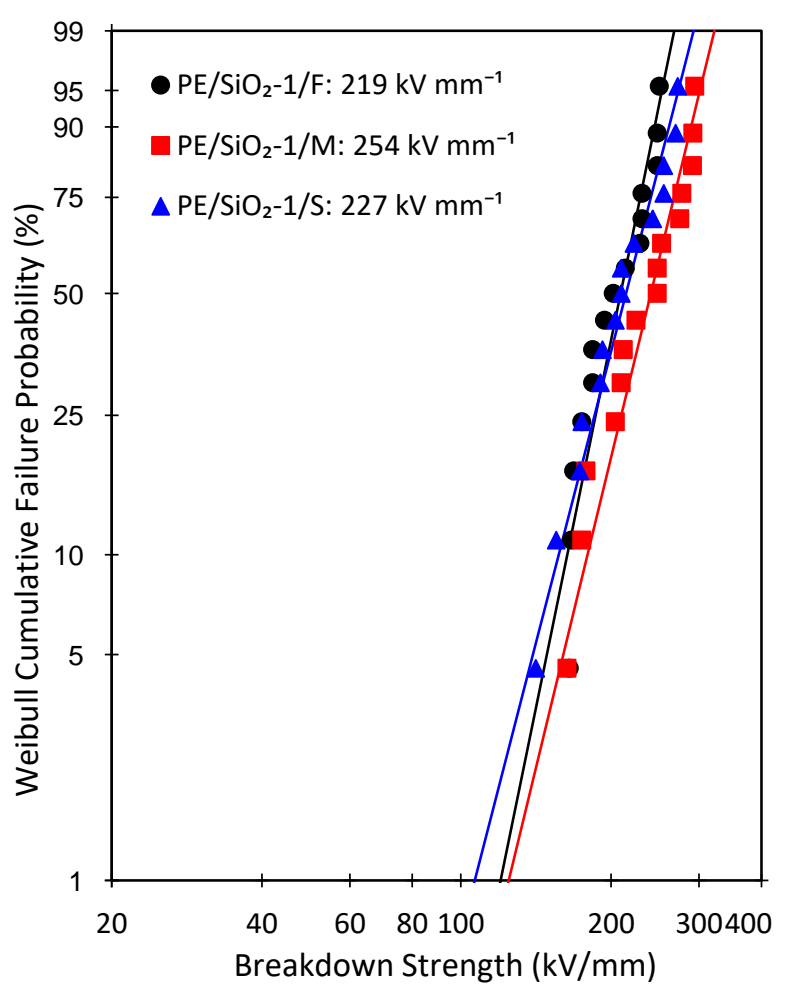

(a)

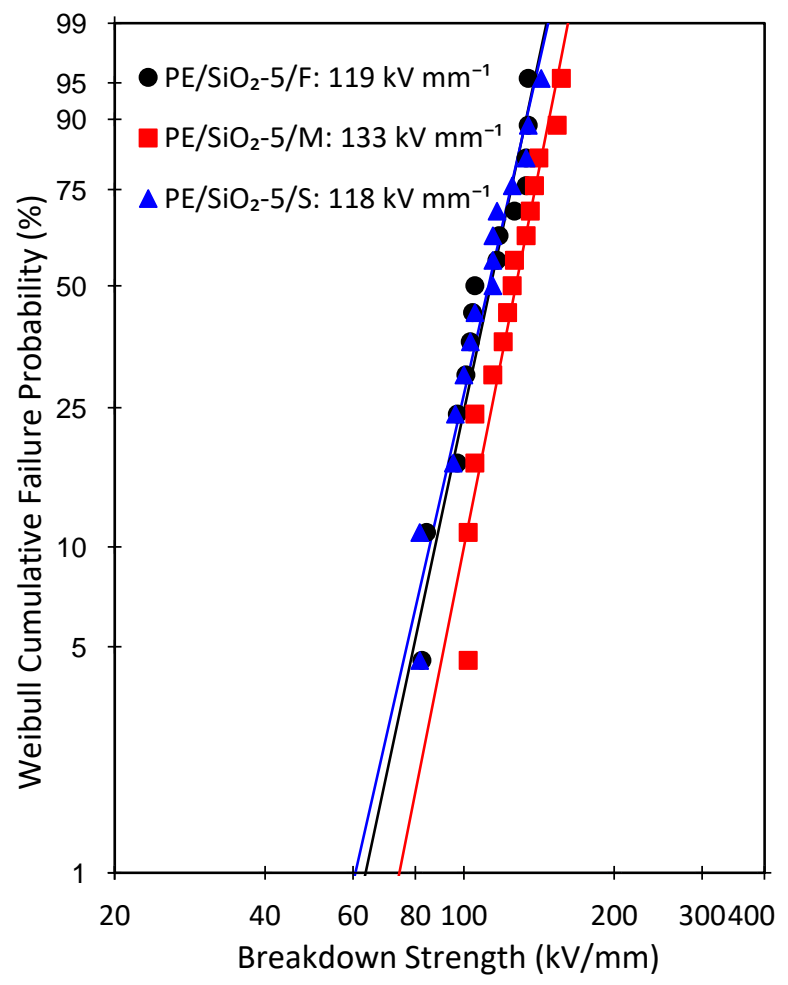

(b)

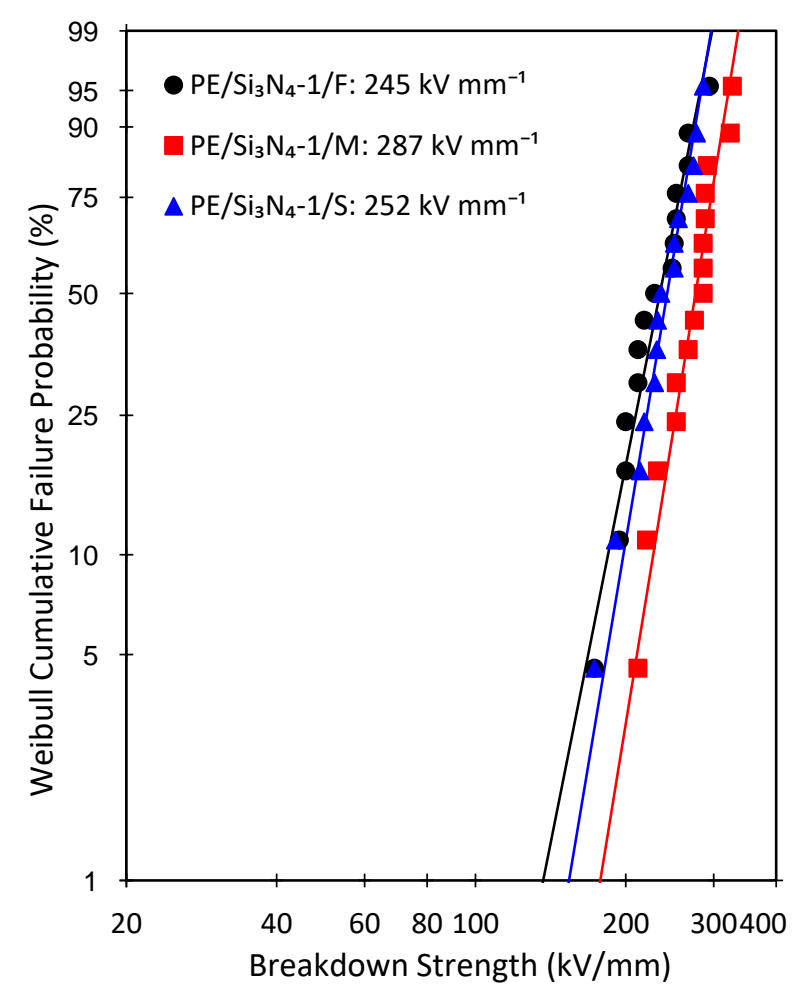

(c)

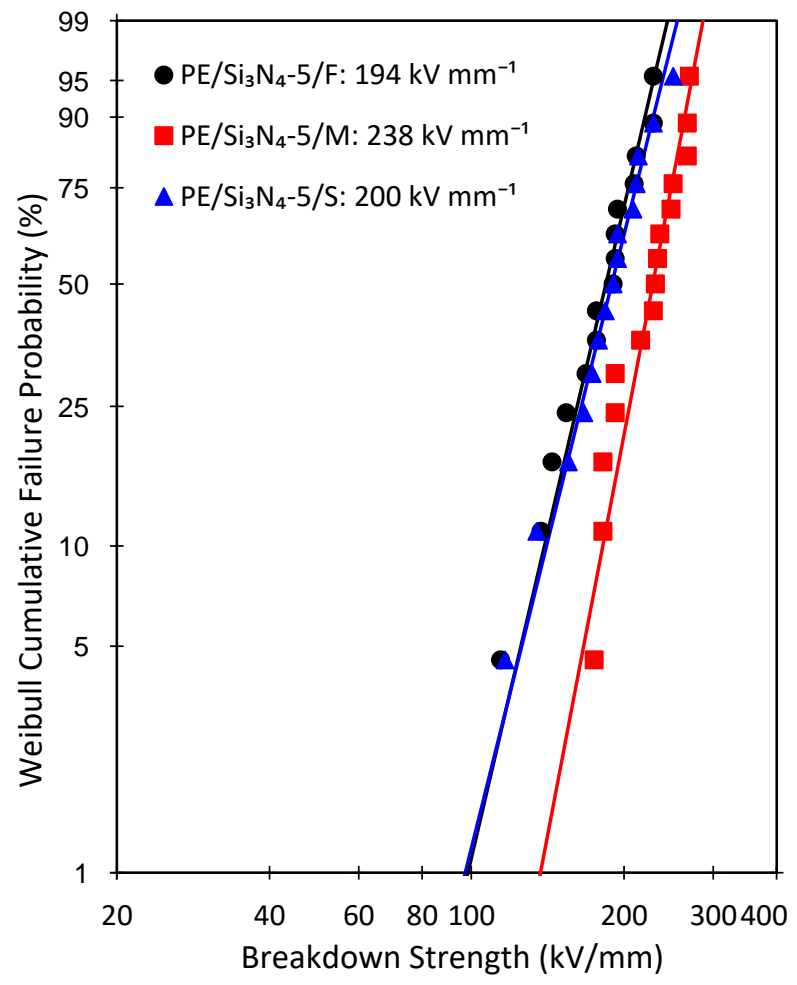

(d)

Fig. 9 Weibull plots comparing DC breakdown strength of nanocomposites containing (a) $1 \mathrm{wt} \%$ of $\mathrm{SiO}_{2}$, (b) $5 \mathrm{wt} \%$ of $\mathrm{SiO}_{2}$, (c) $1 \mathrm{wt} \%$ of $\mathrm{Si}_{3} \mathrm{~N}_{4}$, (d) $5 \mathrm{wt} \%$ of $\mathrm{Si}_{3} \mathrm{~N}_{4}$, under fast, moderate, and slow crystallizations 
Since the influence of crystallization was less pronounced under AC breakdown, the current work suggests that morphological changes of the polymer caused by crystallization were of secondary importance for the investigated nanocomposite systems under AC field, as also highlighted elsewhere. ${ }^{38,42}$ While changes in a single component polymer's morphology can have a direct effect on macroscopic properties of the polymer, variations in a polymer blend's morphology are less directly translated into changes in the macroscopic properties of a polymer blend-based nanocomposite system. ${ }^{10}$

Under DC field, adding $1 \mathrm{wt} \%$ and $5 \mathrm{wt} \%$ of $\mathrm{Si}_{3} \mathrm{~N}_{4}$ to $\mathrm{PE}$ resulted in higher $\mathrm{DC}$ breakdown strength compared to adding equivalent amounts of $\mathrm{SiO}_{2}$ to $\mathrm{PE}$ under the respective fast, moderate, and slow crystallizations (compare Figures $9 \mathrm{c}$ and $9 \mathrm{~d}$ with Figures $9 \mathrm{a}$ and $9 \mathrm{~b}$, respectively). The increased DC breakdown strength of $\mathrm{Si}_{3} \mathrm{~N}_{4}$-based nanocomposites can be attributed to reduced surface hydroxyl groups and associated water molecules in the nanocomposites compared to $\mathrm{SiO}_{2}$-based nanocomposites, as demonstrated through FTIR. Water was therefore having less pronounced effects in $\mathrm{Si}_{3} \mathrm{~N}_{4}$-based nanocomposites than in $\mathrm{SiO}_{2}$-based nanocomposites. In fact, the current comparison between the DC breakdown strength of $\mathrm{Si}_{3} \mathrm{~N}_{4}$-based nanocomposites and $\mathrm{SiO}_{2}$-based nanocomposites reinforces one of the authors' previous assertion that water is the main mechanism affecting the DC breakdown performances of these two nanocomposite systems ${ }^{24}$; similar findings comparing the DC breakdown strength of $\mathrm{PE} / \mathrm{SiO}_{2}$ nanocomposites and $\mathrm{PE} / \mathrm{Si}_{3} \mathrm{~N}_{4}$ nanocomposites have also been reported elsewhere. ${ }^{32}$ This is because the interface within nanocomposites depends largely on the interfacial layer of nanoparticles, and this is closely associated with water molecules governing the surface chemistry of the nanoparticles. Meanwhile, the dispersion state of $\mathrm{SiO}_{2}$ and $\mathrm{Si}_{3} \mathrm{~N}_{4}$ nanofillers in $\mathrm{PE}$ was less influential in DC breakdown since the dispersion state of an equivalent amount of $\mathrm{SiO}_{2}$ and $\mathrm{Si}_{3} \mathrm{~N}_{4}$ was comparable in the current work.

Again, the DC breakdown strength of both the $\mathrm{SiO}_{2}$-based nanocomposites and $\mathrm{Si}_{3} \mathrm{~N}_{4}$-based nanocomposites, when subjected to moderate crystallization, was the highest compared to fast and slow crystallizations, under $1 \mathrm{wt} \%$ and $5 \mathrm{wt} \%$ of nanofiller loading levels (see Figures 9a, 9b, 9c and 9d). These DC breakdown data suggest that changes in crystallization conditions had a more direct consequence under DC field. To correlate the crystallization, structure, and breakdown properties of the materials, the following inferences are made.

SEM morphology of the current work suggests granular-like lamellar structure for all moderately crystallized materials. Since water was present in both $\mathrm{SiO}_{2}$-based nanocomposites and $\mathrm{Si}_{3} \mathrm{~N}_{4}$-based nanocomposites, interfacial water accumulation mechanisms within the materials can therefore be affected by the granular-like arrangement of the lamellar network. As such, mitigation of water-related effects under moderate crystallization was likely, and this in turn resulted in an enhancement of the DC breakdown performance of the materials. Although a sheaf-like lamellar structure has been previously reported to favor breakdown improvements in a polyethylene blend ${ }^{22}$, the current results suggest that this was not applicable for the investigated material systems. In fact, the literature ${ }^{42}$ suggests that, although the breakdown strength of a material can be enhanced under slower crystallizations, the breakdown strength can otherwise be deteriorated when subjected to extremely slow crystallization, as a consequence of the development of a coarser crystal morphology during extremely slow crystallization. ${ }^{43}$

In addition, analysis of crystallinity shows that changes in the melting traces of the HDPE-rich phase were crucial as far as the DC breakdown strength is concerned. The crystallinity of the nanocomposites under fast and slow crystallizations was largely indistinguishable, and so was the breakdown strength. However, each moderately crystallized sample possessed the highest crystallinity compared to the respective sample subjected to fast and slow crystallizations. Since the breakdown strength of all the materials was also the highest under moderate crystallization, this can be attributed to high crystallinity of the materials under moderate crystallization. According to the literature ${ }^{44}$, higher crystallinity of a material can be caused by the presence of increased crystalline regions with well-ordered molecules of the polymer. The crystalline regions, which in turn determines the crystallinity, can also influence water-related interactions within the material 
- water molecules commonly aggregate in the amorphous region, but not in the crystalline region ${ }^{45}$ that will subsequently affect the material's breakdown strength. Therefore, the current results suggest that increased crystalline regions of the moderately crystallized nanocomposites led to well-ordered molecular network (granular-like lamellar structure), whereby the breakdown path became harder to penetrate through the crystalline regions. This resulted in higher breakdown strength of the moderately crystallized nanocomposites.

\section{Conclusions}

In the current work, polyethylene blend nanocomposites containing $1 \mathrm{wt} \%$ and $5 \mathrm{wt} \%$ of $\mathrm{SiO}_{2}$ and $\mathrm{Si}_{3} \mathrm{~N}_{4}$ nanofillers was successfully formulated under three non-isothermal crystallization processes, namely, fast $\left(80{ }^{\circ} \mathrm{C} \mathrm{min}^{-1}\right)$, moderate $\left(15^{\circ} \mathrm{C} \mathrm{min}{ }^{-1}\right)$, and slow $\left(1{ }^{\circ} \mathrm{C} \mathrm{min}^{-1}\right)$ crystallizations. These different nanocomposites and crystallization conditions had different effects on the breakdown performance of the materials. Specifically, nanocomposites containing $\mathrm{Si}_{3} \mathrm{~N}_{4}$ had higher breakdown strength than nanocomposites containing equivalent amounts of $\mathrm{SiO}_{2}$. Since nanofiller dispersion within both nanocomposite systems was comparable, the enhanced breakdown performance of $\mathrm{Si}_{3} \mathrm{~N}_{4}$-based nanocomposites is attributed to changes in the surface chemistry of the silicon-based nanoparticles, where $\mathrm{Si}_{3} \mathrm{~N}_{4}$ has fewer surface hydroxyl groups than $\mathrm{SiO}_{2}$. Meanwhile, moderately crystallized $\mathrm{SiO}_{2}$-based nanocomposites and $\mathrm{Si}_{3} \mathrm{~N}_{4}$-based nanocomposites possessed the highest DC breakdown strength than equivalent nanocomposites subjected to fast and slow crystallizations. This is attributed to changes in the underlying molecular conformation of PE leading to granular-like lamellar structure and increased crystallinity of the moderately crystallized materials, whereby water-related effects became mitigated and that it was more difficult for the breakdown path to penetrate through the well-ordered crystalline region. While engineering surface chemistries of nanofillers, through the removal of surface hydroxyl groups, is critical in enhancing the breakdown performance of nanocomposites, the current work suggests that changes in the underlying molecular conformation of polymers as a consequence of moderate crystallization are also important to improve the breakdown performance of nanocomposites. Significantly, nanocomposites with a higher voltage rating for any given insulation thickness can be achieved through appropriate non-isothermal crystallization processes of the base polymer.

\section{Acknowledgments}

The authors acknowledge Malaysia Ministry of Education, Universiti Teknologi Malaysia, and Nippon Sheet Glass Foundation for Materials Science and Engineering for financial sponsorship and FRGS (FRGS/1/2019/TK04/UTM/02/1), RUG (16J55), and NSG (4B373) research grants.

\section{References}

1. S. Diaham, IEEE Trans. Dielectr. Electr. Insul. 26, 247 (2019).

2. E. Helal, C. Pottier, E. David, M. Frechette, N. R. Demarquette, Eur. Polym. J. 100, 258 (2018).

3. S. Zhou, J. Wang, G. Wang, Z. Jiang, H. Ren, Polym. Bull. 75, 289 (2018).

4. S. P. P. Sadhu, S. Siddabattuni, S. Muthukumar, K. B. R. Varma, J. Mater. Sci. Mater. Electron. 29, 6174 (2018).

5. J. K. Nelson, J. C. Fothergill, L. A. Dissado, W. Peasgood, Ann. Rep. Conf. Electr. Insul. Dielectr. Phenom. 7596363, 295 (2002).

6. S. Okozumi, Y. Murakami, M. Nagao, Y. Sekiguchi, C. C. Reddy, Y. Murata, Ann. Rep. Conf. Electr. Insul. Dielectr. Phenom. 10459487, 722 (2008).

7. M. S. Hamzah, M. Mariatti, M. Kamarol, Polym Bull 75, 2529 (2018).

8. F. N. Alhabill, R. Ayoob, T. Andritsch, A. S. Vaughan, Mater. Des. 158, 62 (2018).

9. D. Pitsa, M. G. Danikas, Nano 6, 497 (2011).

10. I. L. Hosier, M. Praeger, A. S. Vaughan, S. G. Swingler, IEEE Trans. Dielectr. Electr. Insul. 24, 3073, (2017).

11. C. Zhang, G. C. Stevens, IEEE Trans. Dielectr. Electr. Insul. 15, 606 (2008)

12. D. Fabiani, G. C. Montanari, L. Testa, IEEE Trans. Dielectr. Electr. Insul. 17, 221 (2010)

13. S. Li, G. Yin, G. Chen, J. Li, S. Bai, L. Zhong, Y. Zhang, Q. Lei, IEEE Trans. Dielectr. Electr. Insul. 17, 1523 (2010).

14. X. Huang, Z. Ma, Y. Wang, P. Jiang, Y. Yin, Z. Li, J. Appl. Polym. Sci. 113, 3577 (2009).

15. X. Huang, P. Jiang, C. Kim, Q. Ke, G. Wang, Compos. Sci. Tech. 68, 2134 (2008).

16. C. D. Green, A. S. Vaughan, IEEE Electr. Insul. Mag. 24, 6 (2008).

17. I. L. Hosier, A. S. Vaughan, S. G. Swingler, J. Polym. Sci. B Polym. Phys. 38, 2309 (2000).

18. I. L. Hosier, A. S. Vaughan, S. G. Swingler, J. Mater. Sci. 32, 4523 (1997). 
19. K. Y. Lau, A. S. Vaughan, G. Chen, I. L. Hosier, A. F. Holt, J. Phys. D Appl. Phys. 46, 095303 (2013).

20. K. Y. Lau, A. S. Vaughan, G. Chen, I. L. Hosier, A. F. Holt, K. Y. Ching, IEEE Trans. Dielectr. Electr. Insul. 21, 340 (2014)

21. M. L. D. Lorenzo, C. Silvestre, Prog. Polym. Sci. 24, 917 (1999)

22. C. D. Green, A. S. Vaughan, G. Stevens, S. J. Sutton, T. Geussens, M. Fairhurst, IEEE Trans. Dielectr. Electr. Insul. 20, 1 (2013).

23. I. L. Hosier, A. S. Vaughan, A. Pye, G. C. Stevens, IEEE Trans. Dielectr. Electr. Insul. 26, 1197 (2019).

24. K. Y. Lau, S. N. R. M. Zafrullah, I. Z. Ismail, K. Y. Ching, J. Electrostatics 96, 119 (2018).

25. L. Mandelkern, Comprehensive polymer science: polymer properties, 363 (1992).

26. L. Wei, L. Tang, B. Huang, J. Polym. Sci. A Polym. Chem. 42, 941 (2004).

27. D. Panaitescu, S. Moradian, A. Rashidi, M. Yazdanshenas, J. Appl. Polym. Sci. 122, 1921 (2011).

28. L. Dissado, J. Fothergill, Electrical Degradation and Breakdown in Polymers (1992).

29. D. Fournier, L. Lamarre, Ann. Rep. Conf. Electr. Insul. Dielectr. Phenom., 4652915, 229 (1992)

30. A. S. Vaughan, I. L. Hosier, J. Mater. Sci. 43, 2922 (2008).

31. C. D. Green, A. S. Vaughan, G. R. Mitchell, T. Liu, IEEE Trans. Dielectr. Electr. Insul. 15, 134 (2008).

32. C. S. Wu, H. T. Liao, J. Polym. Sci. B Polym. Phys. 41, 351 (2003).
33. Y. Li, L. Wang, S. Yin, F. Yang, P. Wu, J. Am. Ceram. Soc. 94, 4169 (2011).

34. G. Cheng, J. Qian, Z. Tang, G. Ding, J. Zhu, Ceram. Int. 41, 1879 (2015)

35. I. L. Hosier, M. Praeger, A. S. Vaughan, S. G. Swingler, IEEE Trans. Nanotechno. 16, 169 (2017).

36. J. V. Gulmine, P. R. Janissek, H. M. Heise, L. Akcelrud, Polym. Test. 21, 557 (2002).

37. A. Samad, K. Y. Lau, I. A. Khan, A. H. Khoja, M. M. Jaffar, M. Tahir, J. Phys. Chem. Solids 120, 140 (2018).

38. N. H. Rahim, K. Y. Lau, N. A. Muhamad, N. Mohamad, W. A. W. A. Rahman, A. S. Vaughan, IEEE Trans. Dielectr. Electr. Insul. 26, 284 (2019).

39. R. H. Olley, D. C. Bassett, Polymer 23, 1707 (1982).

40. E. Kontou, M. Niaounakis, Polymer 47, 1267 (2006).

41. K. Y. Lau Structure and electrical properties of silicabased polyethylene nanocomposites, PhD thesis University of Southampton (2013).

42. N. H. Rahim, K. Y. Lau, N. A. Muhamad, N. Mohamad, C. W. Tan, A. S. Vaughan, IEEE Trans. Dielectr. Electr. Insul. 26, 1541 (2019).

43. C. D. Green, A. S. Vaughan, G. Stevens, A. Pye, S. J. Sutton, T. Geussens, M. Fairhurst, IEEE Trans. Dielectr. Electr. Insul. 22, 639 (2015).

44. G. Chen, IEEE Int. Conf. High Voltage Eng. Appl. 16558475, 1 (2016).

45. A. Rozanski, A. Galeski, Macromolecules 44, 7273 (2011). 